\title{
13
}

\section{Are Colors Secondary Qualities?*}

\author{
Alex Byrne and David R. Hilbert
}

Color is an affair of the mind, while light is purely physical, but you cannot have one without the other.

The Dangerous Book for Boys

\section{Introduction}

Seventeenth- and eighteenth-century discussions of the senses are often thought to contain a profound truth: some perceptible properties are secondary qualities, dispositions to produce certain sorts of experiences in perceivers. Any apparent plausibility this has often derives, we argue, from an erroneous picture of perception. The colors are typically held to be one of the clearest examples of secondary qualities, and so we shall focus on these.

Since the terminology of "secondary qualities" is liable to produce misunderstanding, some extra clarification won't go amiss. First, for the purposes of this paper, secondary qualities are just stipulated to be dispositions to produce experiences - that is the way this terminology is (mostly) used by the contemporary philosophers we principally discuss. So, for example, Rae Langton's (1998) account of Kant's “primary/ secondary quality distinction" as a distinction between intrinsic and relational properties, and her partial defense of Kant's apparent claim that we can only know the secondary qualities of objects, is not relevant to present concerns. (A Kantian "secondary quality" on Langton's interpretation need not involve relations to perceivers.) Also not relevant are secondary qualities in either of Berkeley's two senses: a quality that exists "nowhere but in the mind" (see Van Cleve 1999: 167); or a quality that is either a color, or a sound, or a taste, or a smell, or... (see Armstrong 1968a: 270).

Second, although arguably Locke was an "eliminativist" about color, and hence did not hold that colors are secondary qualities (see note 24 below), sometimes contempor-

* A remote ancestor of this paper was given at the Central APA in 2002; thanks to the commentator, Justin Broackes. Mark Kalderon provided much help with an even earlier version, as did others whom we have now forgotten. Thanks to an anonymous referee for comments on the penultimate draft. 
ary arguments for the secondary quality theory of color are said to derive from the Essay. We assume that all possible support from this source has trickled into the contemporary literature: accordingly the Essay will be set aside.

The basic schematic claim of the secondary quality theory of color, or dispositionalism, can be illustrated as follows:

(D) The property green $=$ the disposition to cause in perceivers of kind $P$ in conditions of kind $C$, visual experiences of kind $K$.

There are two importantly different ways of specifying the manifestation of the disposition, the "visual experiences of kind $K$ " (cf. Boghossian and Velleman 1989: 84-5). The specification may be non-reductive: the visual experiences are as of a green object. Put more plainly, the experiences consist in the disposed object's looking green to perceivers of kind $P$ (e.g. McGinn 1983). ${ }^{1}$ The relevant interpretation of looks green (etc.) can be explained by example. First, a paradigmatically green object (say, a cucumber) looks green to someone with normal color vision who sees the cucumber in daylight from a few feet away. Second, a white patch illuminated by a small green spotlight, in an array of normally illuminated colored patches, looks green to someone with normal color vision who sees the patch. Third, we may imagine that a certain green car looks a distinctive shade of grey in the artificial light of an underground parking garage. Even though the car can be identified as green by sight in the garage (no car is that peculiar shade of grey), it does not look green to someone with normal color vision who sees it in the garage. (No doubt there is an understanding of looks green on which the green car does look green; this is the "epistemic use" of looks that can be made more explicit by saying that the car looks as if it is green; cf. Jackson 1977: ch. 2.)

On the alternative reductive specification of the "visual experiences of kind $K$ ", the visual experiences are not specified using green or any cognate expressions. Just how they are specified is a tricky issue, which we will discuss at length later (section 3).

The reductive dispositionalist's neck, then, is stuck out the furthest. Everyone can agree, with the non-reductive dispositionalist, that cucumbers are disposed to look green; the bone of contention is whether this disposition is the property green. In contrast, it is disputed whether cucumbers even have a disposition to cause "visual experiences of kind $\mathrm{K}$ ", as the reductive dispositionalist conceives of them. ${ }^{2,3}$

\footnotetext{
${ }^{1}$ On this specification of the manifestation, the otherwise problematic notion of a "visual experience" drops out; on the notion of an "experience" in the philosophy of perception, see Byrne 2009b.

${ }^{2}$ Notice that this constraint on the reductive dispositionalist is compatible with the intentionalist or representationalist view that the phenomenal character distinctive of a color experience is determined by its representational content, the way the experience represents the world as being. Shoemaker (1994) is an intentionalist who thinks that the phenomenal character of a color experience is not determined by its color content - the aspect of its representational content that concerns the colors of things.

${ }^{3}$ It might be claimed that there is a use of looks green on which to describe an object as looking green is not to comment in any way on its color, real or apparent, but rather to characterize the phenomenal character of one's visual experience (this would be similar to the alleged "qualitative sense" of looks the same - see Shoemaker 1982: 365, Block 1990: 54). If so, a reductive dispositionalist could then express her thesis
} 
Sometimes dispositionalism is not put in terms of property identity, but rather as a biconditional claim. For example: necessarily, something is pink iff it's disposed to look pink. (This biconditional formulation might be preferred on nominalist grounds.) We shall (mostly) take dispositionalism to be an identity claim, but this assumption is only for convenience. In any case, on the (defensible) view that necessary coextensiveness is sufficient for property identity, the biconditional and identity formulations are equivalent. ${ }^{4}$

One common objection to dispositionalism is that there are problems with specifying the dispositionalist's "perceivers" and "conditions" in a principled manner (see, e.g. Hardin 1993: 67-91). Although this is a serious problem, we shall ignore it, chiefly because we think the deeper difficulties lie elsewhere. ${ }^{5}$

\section{Colors might be (non-reductive) dispositions}

Having advertised this paper as an anti-dispositionalist manifesto, we now must confess that colors might, after all, be dispositions to affect perceivers in certain ways. ${ }^{6}$ Maybe there could be some especially well-calibrated type of perceiver, and some particularly revealing conditions, such that necessarily something is blue iff it is disposed to look blue to this type of perceiver in these revealing conditions, and similarly for the other colors. Without making controversial assumptions about colors and color perception, it is hard definitively to rule this out. If such a biconditional is true, and granting that necessary coextensiveness is sufficient for property identity, then non-reductive dispositionalism is true. ${ }^{7,8}$

using looks green (see Boghossian and Velleman 1989: 85). We do not think there is such a use, but in any case it does not occur here.

${ }^{4}$ McGinn has recently retracted his position in The Subjective View (1983) that colors are dispositions to look colored, and retreated to the claim that they are necessarily coextensive with such dispositions (1996). (So, of course, he is obliged to deny that necessary coextensiveness is sufficient for property identity.) Although the identity claim is the official target of this paper, the overall argument works equally well against either the identity or biconditional formulations of dispositionalism.

${ }_{5}^{5}$ For a response to Hardin, see Johnston 1992: 155-8.

${ }^{6}$ On some views, colors are certain kinds of dispositions to reflect light (Hilbert 1987, Matthen 1988, Tye 1995, Byrne and Hilbert 1997a, Tye 2000), not dispositions to affect perceivers.

7 It might be objected that the truth of such a biconditional (granted that necessary coextensiveness is sufficient for property identity) would merely establish that any color could be (rigidly) designated by a dispositional locution, which is not sufficient for a property to be a disposition (cf. Jackson 1998: 94). Be that as it may, for the purposes of this paper we can be concessive to the dispositionalist: if the colors can be designated by dispositional locutions involving perceivers and conditions not too far removed from actual human beings and the actual conditions in which they see objects, then (given the assumption about property identity) dispositionalism is true. With this concession, the objection to dispositionalism based on the premise that "dispositions do not cause their manifestations, their causal bases do that" is to some degree finessed. The objection needs the principle that dispositions are distinct from their causal bases, and the main argument for this principle fails on the present catholic notion of a disposition. (For the principle and the argument, see Prior et al. 1982: 253-4. For the objection, see Jackson and Pargetter 1987, Jackson 1998: 91-3. For the reply that Jackson and Pargetter's "primary quality" theory of color suffers from a similar defect, see Johnston 1992: 148-9.)

8 Admittedly, any dispositional account has to face some serious objections in the style of Kripke's "killer yellow" example (e.g. Broackes 1992: 203-4). Surely there could be a yellow object (Medusa's face, say) that would instantly kill anyone who looked at it. So if someone were to gaze at Medusa, her face would not look 
Of course, if the above speculations turned out to be correct, this would only vindicate dispositionalism in letter, not in spirit. The dispositionalist typically takes her thesis to be justified on a priori grounds, or at least on the basis of ordinary color experience: recherché empirical investigation is not necessary. And that is what we dispute. Dispositionalism - at any rate of the non-reductive variety - is perfectly coherent, but cannot be established a priori, or by reflection on ordinary visual experience.

\subsection{Circularity}

There is, however, an aura of disreputability surrounding non-reductive dispositionalism, deriving from its circularity. Recall that according to the non-reductive dispositionalist:

$\left(D_{\mathrm{NR}}\right) \quad$ The property green $=$ the disposition to look green to perceivers of kind $P$ in conditions of kind $C$.

The circularity of this thesis is evident on its face: green appears univocally on both sides of the identity predicate. The mere fact that a statement of property identity is circular is not itself a cause for concern: modulo the existence of properties, the property green = the property green can hardly be problematic! Neither does circularity imply that the thesis is trivial: the property square = the disposition to look square is not trivial; indeed, it is usually regarded as false. (Cf. Boghossian and Velleman 1989: 87-8.)

However, there is a legitimate worry about circularity if the non-reductive dispositionalist is not content merely to make a claim about property identity. The crucial distinction can be seen in Sellars's Empiricism and the Philosophy of Mind. ${ }^{9}$ When Sellars first discusses non-reductive dispositionalism he takes it to be an attempt at "a definition of physical redness in terms of looking red" (1956, sec. 12) and claims without argument that it is objectionably circular. When he later (sec. 18) finds ostensibly the same thesis unproblematic it is because, although he takes it to be knowable a priori, he no longer understands it as offering a "definition", or an "analysis", of " $x$ is red ... in terms of $x$ looks red to $y$ ".

Although it's not particularly clear what Sellars takes a definition to be, the circularity worry is clear enough. If $\left(\mathrm{D}_{\mathrm{NR}}\right)$ is taken to provide a way of explaining what redness is, to someone who is entirely ignorant of it, or to provide a synonym of the word red, then the fact that red appears in the explanans, or in the allegedly synonymous phrase, is a glaring obstacle. If someone has absolutely no idea what redness is, we can hardly presume that he understands the word. And given a modest assumption about meanings or semantic values red cannot be synonymous with a phrase containing looks red.

yellow to that person. If it follows that Medusa's face is not disposed to look yellow, then this is a counterexample to dispositionalism. But this sort of case is usually taken instead to be a counterexample to a simple counterfactual analysis of dispositions (see Johnston 1992: 145-7 and also Lewis 1997a: 144-5, 1997b: 334-5).

9 Although he doesn't discuss Sellars, Watkins (1994) makes the distinction quite nicely. 
The semantic value of the larger phrase is presumably composed of the semantic values of its constituents, which include looks and red. If so, identifying the semantic value of red with the semantic value of the larger phrase is in effect to (incorrectly) identify a proper part with the whole.

Another example of this sort of concern is provided by Christopher Peacocke. After claiming that "visual experience seems to occupy a special position in an explanation of what it is for something to be red", he points out the difficulty:

[This is] precisely what we should expect if looking red is conceptually more fundamental than being red. Yet on the other hand the expression "looks red" is not semantically unstructured. Its sense is determined by that of its constituents. If one does not understand those constituents, one does not fully understand the compound.

(1984: 51-2)

Non-reductive dispositionalism, as we are understanding it, is simply a claim of property identity, and makes no claims about analysis, synonymy, or conceptual priority. One might have thought, then, that while circularity undermines some dispositionalist projects, it leaves non-reductive dispositionalism unscathed. However, Boghossian and Velleman have influentially argued that the circularity of $\left(\mathrm{D}_{\mathrm{NR}}\right)$ is actually fatal. Their argument has persuaded some (e.g. Averill 1992: 556, McGinn 1996: 543-4, Levin 2000, Glüer 2007) but, we will now argue, it shouldn't have. ${ }^{10}$

\subsection{Boghossian and Velleman's circularity argument}

Boghossian and Velleman express non-reductive dispositionalism thus:

(*) "Red [i.e. the property that objects are seen as having when they look red] $=_{\text {def }}$ a disposition to appear red under standard conditions" (1989: 84)

This appears to be a simple statement of property identity (and so is a minor variant of $\left(\mathrm{D}_{\mathrm{NR}}\right)$ ), and Boghossian and Velleman gloss it as such: "the property that objects are represented as having when they look red is just this: a disposition to look red under standard conditions" (84). ${ }^{11}$

They then argue as follows:

Under the terms of $\left[\left(^{*}\right)\right]$, an experience can represent its object as red only by representing it as disposed to produce visual experiences that represent it as red. The problem here is that the experiences that the object is thus represented as disposed to produce must themselves be represented as experiences that represent the object as red, rather than some other colour-lest

\footnotetext{
${ }^{10}$ A similar-if not identical-objection to non-reductive dispositionalism is in Stroud 2000: 140-3. There is a complicated and rather distantly related objection in Johnston 1998: 13-5, and Johnston 2001b: 195-9; for discussion see Wedgwood 2001 and Johnston 2001a.

11 Boghossian and Velleman actually describe $\left(^{*}\right)$ as a "biconditional"; taking it as an identity statement seems more faithful to their overall intent. The presence of def in $\left(^{*}\right)$ might suggest that it is a metalinguistic claim: red is synonymous with the disposition to appear red, or something of the sort. But this would certainly be a misreading. Boghossian and Velleman presumably have in mind Aristotelian real definitions. In this sense, to give the real definition of a thing is to specify its nature.
} 
the object be represented as disposed to appear something other than red. Yet these experiences can be represented as representing the object as red only if they are represented as representing it as disposed to produce experiences that represent it as red. And here the circle gets vicious. In order for an object to appear red rather than blue, it must appear disposed to appear red, rather than disposed to appear blue; and in order to appear disposed to appear red, rather than disposed to appear blue, it must appear disposed to appear disposed to appear red, rather than disposed to appear disposed to appear blue; and so on. Until this regress reaches an end, the object's appearance will not amount to the appearance of one colour rather than another. Unfortunately, the regress never reaches an end.

The problem with the regress is summarized later:

[T] he subject of visual experience cannot see what colour an object has. For he cannot see that particular colour of an object except by seeing the particular way the object tends to appear; and he cannot see the way it tends to appear except by seeing the way it tends to appear as tending to appear; and so on, ad infinitum.

The argument may be reconstructed as follows (suppressing the reference to standard conditions):

$\left(A_{1}\right) \quad$ The property red $=$ the disposition to appear (look) to have the property red.

By $\left(A_{1}\right)$, substituting the right hand side for the property red throughout:

$\left(\mathrm{A}_{2}\right)$ The disposition to appear to have the property red $=$ the disposition to appear to have the disposition to appear to have the property red.

And so on. In an obvious notation:

$\left(A_{n+1}\right) \quad[\text { The disposition to appear to have }]^{n}$ the property red $=[$ the disposition to appear to have $]^{\mathrm{n}+1}$ the property red.

Now suppose:

$\left(B_{1}\right)$ The fire truck appears (looks) to Griffin to have the property red. ${ }^{12}$

Then, by $\left(A_{1}\right)$, substituting its right hand side for the property red:

$\left(B_{2}\right)$ The fire truck appears to Griffin to have the disposition to appear to have the property red.

And by $\left(\mathrm{A}_{2}\right)$, substituting its right hand side for the disposition to appear to have the property red:

\footnotetext{
12 Since the exposition will be simplified if the substituends are noun phrases rather than verb phrases, we have used the fire truck appears to Griffin to have the property red as opposed to the more natural the fire truck appears red to Griffin. But this is just for convenience.
} 
$\left(B_{3}\right)$ The fire truck appears to Griffin to have the disposition to appear to have the disposition to appear to have the property red.

And so on. By $\left(A_{3}\right), \ldots,\left(A_{n}\right)$ :

$\left(B_{n+1}\right)$ The fire truck appears to Griffin to have [the disposition to appear to have $]^{\mathrm{n}}$ the property red.

(C) By the B-series, Griffin cannot see the particular color of the fire truck except by seeing the particular way the fire truck tends to appear; and he cannot see the way it tends to appear except by seeing the way it tends to appear as tending to appear; and so on, ad infinitum. Hence he cannot see it as having a color, which is absurd. And so, by reductio, $\left(\mathrm{A}_{1}\right)$ is false.

Let us look at the A-series of inferences first. On the (natural) non-transparent de dicto reading of appear to have..., they are invalid. So-putting aside the question of Boghossian and Velleman's intentions - appear to have ... must be read transparently. ${ }^{13}$ On this reading, The fire truck appears to have the disposition to appear to have the property red is true just in case there is a property $\mathrm{P}$ such that the fire truck appears to have it, and $\mathrm{P}$ is the disposition to appear to have the property red. So understood, the A-series is unobjectionable.

What about the inferences in the B-series? On the de dicto reading of The fire truck appears to Griffin to have..., they are invalid. So-again putting aside the question of Boghossian and Velleman's intentions-The fire truck appears to Griffin to have... must be read transparently. On this reading, The fire truck appears to Griffin to have the disposition to appear to have the property red is true just in case there is a property $\mathrm{P}$ such that Griffin sees that the fire truck appears to have it, and $\mathrm{P}$ is the disposition to appear to have the property red. So understood, the B-series is also unobjectionable.

That leaves $(\mathrm{C})$, the final part of the argument. To rebut it, note that given the assumptions required to generate the B-series $\left(\left(^{*}\right)\right.$ and the transparent readings), each member of the series demands exactly the same of Griffin: that, of the property red (i.e. the disposition to appear to have the property red, i.e. the disposition to appear to have the disposition...), the fire truck appears to Griffin to have it. Hence, although it is true (given the assumptions just mentioned) that Griffin cannot see the color of the fire truck except by seeing the particular way the fire truck tends to appear, this is a feat he can easily manage: he just needs to see the property that is the color of the fire truck, namely red. He is not required, as Boghossian and Velleman claim, "to run an endless gamut of visual appearances" (89).

\footnotetext{
${ }^{13}$ As McGinn observed in a related context $(1983,143)$. Subsequently, though, he characterized this observation as having been made "somewhat desperately...the maneuver does nothing to avert the fundamental intuitive point that [dispositionalism] is phenomenologically incorrect: we just do not see colors as dispositions to cause experiences" $(1996,538)$. Boghossian and Velleman make a similar claim (see the following note, and note 25 below).
} 
To conclude: if the A- and B-series inferences are valid, $(\mathrm{C})$ is invalid, and therefore so is the reconstructed argument against non-reductive dispositionalism. ${ }^{14}$

\section{The natural sign theory and reductive dispositionalism}

Thus far, we have distinguished two sorts of dispositionalism, and argued that the circularity of non-reductive dispositionalism is unproblematic. It is now time to consider the main question of this paper: is either sort of dispositionalism true?

Let us start with reductive dispositionalism, historically the favored variety; subsequent sections will focus on non-reductive dispositionalism. The main motivation for reductive dispositionalism is a picture of perception that we shall call-borrowing some terminology from Thomas Reid-the natural sign theory. According to it, color perception (for example) is a matter of figuring out the colors of objects in the environment from the distinctive mental effects they cause in us, the "natural signs" of colors. ${ }^{15}$ As will be apparent, once the natural sign theory is assumed, (reductive) dispositionalism is not far behind.

\footnotetext{
14 Two other points are worth noting. First, Boghossian and Velleman really do seem to insist on the de dicto reading of constructions like appears to have... : before arguing that $\left(^{*}\right)$ is viciously circular they give another argument against it, starting from the premise that colors do not look like dispositions (86). This earlier argument would make little sense if they had transparent readings in mind. In any event, even if we temporarily concede that $\left(^{*}\right)$ does generate the B-series read de dicto, (C) still fails. True, each member of the B-series now does demand something different of Griffin, but this is only a concern if in order for the fire truck to appear to Griffin to have [the disposition to appear to have] ${ }^{\mathrm{n}}$ the property red, the fire truck must to appear to Griffin to have [the disposition to appear to have] ${ }^{\mathrm{n}+1}$ the property red first, which generates a problematic infinite temporal regress. However, the argument gives no reason to suppose that there is such a temporal dependence between members of the B-series: Griffin might be able to comply with their demands simultaneously. Of course, if the dispositionalist is committed to these de dicto readings, she's in big trouble, because it's false (read de dicto) that, for all $\mathrm{n}$, the fire truck appears to Griffin to have [the disposition to appear to have $]^{\mathrm{n}}$ the property red. This is another argument entirely, to which the right response is to deny the commitment to the de dicto readings. It does not seem to be an argument that Boghossian and Velleman have in mind, however. Second, immediately before the passages quoted above, there is the following gloss on the argument to come:
}

[The dispositionalist] says that the content of the visual experience of red must contain, as a proper part, the content of the visual experience of red. To see something as red, according to $\left[\left(^{*}\right)\right]$, is to have an experience whose content is that the thing is disposed to produce visual experiences with the content that it is red. The experiential content that something is red is thus embedded within itself, and this is a reflexive relation that no determinate content can occupy.

(This, by the way, is more confirmation that the de dicto reading of appears that ... is intended.) This quotation suggests, not the bad regress argument, but a much better argument of the sort we mentioned when discussing non-reductive dispositionalism as supplying a synonym of red in the previous section. Here is how such an argument would go in the case of "the experiential content that something is red". Assume that propositions are structured entities of either a Fregean or Russellian sort; hence, the proposition that something is red has, inter alia, the sense of red, or the property red, as a constituent. Then the proposition that something is red is not identical to the proposition that something is disposed to look red (the latter has more stuff in it than the former). However, this argument does not seem to fit at all well with the longer quotation given in the text, and is directed against a position that any sensible dispositionalist will not hold.

${ }^{15}$ Talk of a property's causing such-and-such is shorthand for something along the lines of: o's having the property at time $\mathrm{t}$ causes such-and-such. For our purposes, further precision is unnecessary. 
Not only are reductive dispositionalism and the natural sign theory often found in bed together, but also the natural sign theory itself can seem like the merest common sense. This is probably part of the explanation of why dispositionalism continues to retain its appeal.

Mark Johnston alluringly expresses the natural sign theory as follows:

Consider two familiar philosophical cartoons by which the traditional skeptical problem of the external world is typically presented - the case of the eternal movie buff and the case of the brain in the vat... In both cartoons sensory experience is clearly depicted as simply an effect of external causes whose natures are in no way revealed by the experiences they cause. Sensory experience in no way acquaints the brain or the buff with the nature of the external causes of that experience. In this respect, sensory experience is unsatisfyingly like Morse code transmission: both involve interpretable effects at the end of an information-bearing process or signal. But the intrinsic natures of the originators of the signal are not manifest in the signal. This is a very depressing comparison.

(1992: 166)

This picture is also expressed — equally alluringly_by Descartes at the beginning of The World or Treatise on Light:

In proposing to treat here of light, the first thing I want to make clear to you is that there can be a difference between our sensation of light (i.e. the idea that is formed in our imagination through the intermediary of our eyes) and what is in the objects that produces that sensation in us (i.e. what is in the flame or in the sun that is called by the name of "light". For, even though everyone is commonly persuaded that the ideas that are the objects of our thought are wholly like the objects from which they proceed, nevertheless I can see no reasoning that assures us that this is the case. On the contrary, I note many experiences that should cause us to doubt it.

You well know that words bear no resemblance to the things they signify, and yet they do not cease for that reason to cause us to conceive of those things, indeed often without our paying attention to the sound of the words or to their syllables. Thus it can happen that, after having heard a discourse, the sense of which we have very well understood, we might not be able to say in what language it was uttered. Now, if words, which signify nothing except by human convention, suffice to cause us to conceive of things to which they bear no resemblance, why could not nature also have established a certain sign that would cause us to have the sensation of light, even though that sign in itself bore no similarity to that sensation? Is it not thus that she has established laughter and tears, to cause us to read joy and sorrow on the faces of men?

$(1664 / 1985: 81)^{16,17}$

Perception, on this view, is the process of discerning the layout of one's environment on the basis of the mental effects caused by external things. What are those mental effects?

\footnotetext{
${ }^{16}$ Note that Descartes" "signs" are the causes of our sensations; the "natural signs" of the natural sign theory are the sensations themselves.

${ }^{17}$ For another notable expression of the natural sign theory, see Russell 1912: ch. 1.
} 


\subsection{Effects as sensations}

Descartes gives one historically popular answer: "sensations". So, for example, when one perceives a blueberry, among the sensations one receives are some of a distinctive chromatic sort-blue* sensations, we can call them. These blue* sensations are all one has to go on as far as the blueberry's color is concerned. What properties might one reasonably take the blueberry to have, given that it is currently causing one to have blue* sensations? A little experimentation soon shows that the effect is quite robustunder many changes of the lighting or the viewing angle, blue* sensations still result. The blueberry, then, likely has a disposition to cause one to have blue* sensations in normal conditions. Further, since other perceivers are similar to oneself, it likely has a disposition to cause normal perceivers to have blue* sensations in normal conditions. And this second disposition is the obvious candidate to be the referent of the English word blue: it is a disposition that is not specified in terms of particular individuals (e.g. oneself), but rather the general class of normal perceivers; blueberries may safely be taken to have it; and (like the color blue) it is a property that blueberries have when they are not being observed. Thus, reductive dispositionalism is established.

What is a "blue* sensation" supposed to be? Since this is a technical expression, some explanation is required. The usual implicit answer is that it is a chromatic counterpart of a sensation in the ordinary sense- a sensation of pain or heat, for example. And sensations in the ordinary sense are - at least on one traditional view-mere affectations of the mind; they are not intentional or representational states or events. " $[\mathrm{I}] \mathrm{n}$ sensation", Reid writes, "there is no object distinct from the act of the mind by which it is felt — and this holds true with regard to all sensations" (Reid 1785/1941: II.16).

The inadequacy of reductive dispositionalism explained in terms of this Reidian conception of blue* sensations can be illustrated by challenging an example of Wittgenstein's:

Let us imagine the following: the surfaces of the things around us (stones, plants, etc.) have patches and regions which produce pain in our skin when we touch them. (Perhaps through the chemical composition of these surfaces. But we need not know that.) In this case we should speak of pain-patches on the leaf of a particular plant just as at present we speak of red patches. I am supposing that it is useful to us to notice these patches and their shapes; that we can infer important properties of the objects from them.

(Wittgenstein 1958: sec. 312)

In fact, Wittgenstein's hypothetical scenario is not so distant. The leaves of stinging nettles produce pain in our skin and can be described as painful; moreover, it is useful to us to notice this fact. ${ }^{18}$ If the parallel with color is as close as Wittgenstein claims, then dispositionalism (about color) is true, because dispositionalism is clearly correct as an account of painful leaves: a leaf is painful just in case it is disposed to produce pain in the

\footnotetext{
18 And not just for the obvious reason that it is useful to avoid walking through a patch of nettles: the irritants in the leaves have a variety of medicinal uses.
} 
skin of normal subjects in normal conditions, or something along similar lines. To say this is just to recapitulate the easy slide to dispositionalism from the natural sign theory.

However-pace Wittgenstein - the parallel is not at all close, as indicated by the twin facts that (a) nettle leaves do not appear (or feel) painful as red patches appear (or look) red, and (b) we do not speak of visual sensations when looking at a red patch. (At any rate, the common man uncontaminated by philosophy does not speak of visual sensations.)

Concerning (a), imagine that you put your hand in your pocket and then feel a stinging sensation in your hand. You might conjecture that your hand brushed against something in your pocket that caused the sensation, perhaps the leaf of a stinging nettle. The stinging sensation itself gives you no external object to single out and think that it is disposed to cause stinging sensations. If you empty your pocket and only find a harmless piece of fluff, there is no temptation to think that the piece of fluff (misleadingly) appeared or felt painful. Similarly, if you discover that your pocket is empty, there is no temptation to think that you were hallucinating a painful object. Contrast peering into your pocket and seeming to see something red. You may wonder whether that thing really is how it looks or appears, namely red. If that thing is not red, then you are misperceiving it; if there is no object there at all, then you are having some kind of color hallucination.

Concerning (b), when you look into your pocket, you are aware of the red object there, if there is one; you can attend to that object, and wonder whether it is a red $\mathrm{M} \& \mathrm{M}$, for instance. But there is no visual counterpart of the sensation of pain, no "red* sensation" in your eyes, or head, or mind. At least, if there is such an item, it is remarkably self-effacing, not at all like a stinging sensation.

\subsection{Effects as sense-data}

If the sensory effect of the blueberry is not a mere affectation of the mind, what else could it be? Another historically popular answer is that the blueberry produces an awareness of a distinctive sort of sense-datum, an entity that is (in some sense) "minddependent", and that has the properties that it appears to have. On this view, the effect of the blueberry is an intentional state - to be aware of a sense-datum is for the mind to be "directed on" an object, namely the sense-datum itself.

Suppose, then, that blueberries cause normal perceivers to become aware of sensedata of a distinctive kind-blue† sense-data, let us say. This proposal at least has the merit of describing visual experience somewhat more faithfully than the Reidian proposal we previously considered. That proposal located the sensuous chromatic character of vision in "sensations", entirely detached from any object. At least the present proposal locates it where it belongs, in the objects of vision.

On the sense-datum version of reductive dispositionalism, something is blue if and only if it is disposed to cause (awareness of) blue $\dagger$ sense-data in normal perceivers, or something along these lines. But what is the property blue†? Of course, if this account stands a chance of working, it cannot be the property blue. The problem is that, given 
the way sense-datum terminology is usually introduced, it is. Here, for example, is G. E. Moore's explanation:

[I]n order to point out to the reader what sort of things I mean by sense-data, I need only ask him to look at his own right hand. If he does this he will be able to pick out something (and, unless he is seeing double, only one thing) with regard to which he will see that it is, at first sight, a natural view to take that that thing is identical, not, indeed, with his whole right hand, but with that part of its surface which he is actually seeing, but will also (on a little reflection) be able to see that it is doubtful whether it can be identical with the part of the surface of his hand in question. Things of the sort (in a certain respect) of which this thing is, which he sees in looking at his hand, and with regard to which he can understand how some philosophers should have supposed it to be the part of the surface of his hand which he is seeing, while others have supposed that it can't be, are what I mean by "sense-data".

(1959: 54)

For the sake of the argument, let us agree that when looking at one's right hand, one sees an object $o$ that one would offhand take to be part of the hand's surface, but doubt such an identification "on a little reflection". Further, let us grant (as Moore goes on to argue) that $o$ is not, in fact, identical to any part of the surface of one's hand. What must $o$ be like, in order to be easily mistaken by sight for a region of skin? Presumably $o$ must be a colored patch of some sort, and of course that is precisely what Moore and every other sense-datum theorist thought. Here are some examples collected by Firth:

[O]ur sense-datum when we look at a dog, according to Russell, is "a canoid patch of colour". And when we look at a penny stamp, according to Broad, our sensum is "a red patch of approximately square shape". And when we look at an apple, according to Lewis, what is given is a "round, ruddy ... somewhat". And when we look at a tomato, according to Price, our sense-datum is "a red patch of a round and somewhat bulgy shape."

(1949: 438)

The sense-datum version of reductive dispositionalism is therefore unworkable, even granting the existence of sense-data, because sense-data, if there are such things, are evidently colored. If the sense-datum theory is true, then eliminativism is the correct theory of color: public objects like tomatoes and penny stamps from the reign of George $\mathrm{V}$ are not colored. ${ }^{19}$

\subsection{Peacocke's proposal}

So far, we have looked at two candidates for the distinctive mental effect that according to the natural sign theory is produced by a colored object: a non-intentional sensation, and (an awareness of) a sense-datum. If the effects are non-intentional sensations, then non-reductive dispositionalism is hard to resist, but there do not appear to be any such

\footnotetext{
${ }^{19}$ It might be replied that color terms are ambiguous. In one sense they denote properties of sense-data; in another sense they denote different properties of objects like tomatoes and penny stamps. Although there is no evidence of any such ambiguity, Moore later held this view; for a recent defense see Brown 2006, and for further discussion see Byrne 2009a. Of course, there is no inconsistency in supposing that both sense-data and public objects are colored, just complete lack of motivation. See also the following section.
} 
sensations. If, on the other hand, the effects are sense-data, then the supported theory of color is eliminativism rather than dispositionalism.

The chief problem with the sense-data option is that, if sense-data exist at all, they are obviously the color bearers. But that is only true on what we might call the "classical" conception of sense-data. And in fact Peacocke has defended an alternative conception of sense-data on which they are not colored. So let us turn to the details of his account.

Suppose one sees a red poker chip tilted at an angle. The chip looks red and circular. According to a classical sense-datum theorist, one sees a red elliptical sense-datum. According to Peacocke, one is, or can be, aware of an elliptical region of one's "visual field"- a curved plane in space that Peacocke locates (in the monocular case) at the retina (2008: 11). If this elliptical region were opaque, it would exactly occlude the circular chip, and the region has a property that Peacocke calls red'; in additional Peacockean terminology, red' is an example of a sensational property. The sensational property red' is not, on Peacocke's view, the property red, hence the "prime" notation. Peacocke's "visual field", then has spatial properties, but it is not colored.

Given this conception, it is no surprise that Peacocke is a reductive dispositionalist: an object is red, he thinks, iff it is disposed "in normal circumstances to cause the region of the visual field in which it is presented to be red' in normal humans" (1983: 39; see also 1984: 60).

In his early book Sense and Content (1983), in which the "prime" notation was introduced, Peacocke attached primes to spatial as well as color predicates. On this initial version of Peacocke's view, the poker chip case involves an elliptical' region of the visual field, which is (presumably) not an elliptical one. And since Peacocke clearly did not think it had some other shape, this implies that the "visual field" is not itself composed of spatial regions, any more than it is composed of colored regions. But now we have a serious puzzle, because insofar as Peacocke's talk of a visual field is intelligible at all, it apparently makes perfectly good sense to apply spatial vocabulary to both regions and external objects. For instance: "The region of the visual field in which the poker chip is presented, and this drawing, are both elliptical", and "This pencil points upwards in the visual field". As Peacocke has recently observed, remarks of this sort seem "impossible to make sense of... under the hypothesis that spatial talk in describing sensational properties is not to be taken literally" (2008: 12). For this and other reasons, Peacocke now holds that "the visual field is related to, indeed is located in, real space. Location, distance, size and shape in the visual field are spatial properties and relations in a genuinely spatial plane" (11).

Why do not similar considerations also show that regions of the visual field are colored? Imagine looking at the tilted poker chip. According to Peacocke, one may attend to the relevant elliptical region of one's visual field, and to the distinctive property, red', that it has. Granted that there is such a property, what could it possibly be, if not the color red, or at least a color? Can't we literally speak of it as dark, or saturated, or similar to orange, for example? 
Admittedly, if red' = red, and so a region of space located at the retina is literally red when the subject is looking at a tomato in good light, then this is a very surprising discovery about color. Whether or not such a region is red will depend on the sort of experience the perceiver is currently having-according to Peacocke, red $^{\prime}$ regions of one's visual field can be erased simply by turning down the lights, for example. But if physical objects like tomatoes are colored at all, their colors are not similarly sensitive to the perceptual experiences of perceivers - unseen tomatoes remain red, or so we suppose. That is one reason why it is hard to maintain that the visual field and physical objects like tomatoes are both colored. Another reason is simpler: if the visual field were colored, this would apparently prevent the subject from seeing the alleged colors of tomatoes; it might even prevent the subject from seeing tomatoes, which would really be a disaster. (The idea that the visual field is colored but translucent, like a sheet of cellophane, could hardly be more phenomenologically inapt.)

Peacocke agrees that if the visual field is colored, physical objects aren't; since he thinks it is clear that physical objects are colored, he concludes that the visual field isn't. He writes:

Being red is a public property of a physical surface; or of a solid, for example a lump of red Murano glass; or of light, as with a neon sign, a ray of theatre light, or a red firework exploding in the sky. A region of the visual field is not of any of these sorts. If the visual field were literally red, one would be faced with absurd issues: why is it not itself perceived, why cannot many people perceive it? This is why sensational properties should be characterized as primed properties.

(2008: 10)

If the Peacockean visual field has "primed properties", such as red', and if physical objects like tomatoes are red, then there are compelling reasons to deny that red $^{\prime}=$ red. But none of this shows that there are any primed properties in the first place. Indeed, the existence of such things is highly doubtful. Return to the example of the red poker chip. One may adopt the "pictorial attitude" (cf. Peacocke 1983: 23-4), and switch attention from the chip's circular shape and red color to the elliptical shape that it projects on a plane parallel to the line of sight. Such an attention switch does not change what color one is attending to, and still less introduces some new non-color property.

What is wanted is an actual case where a red' region is unaccompanied by awareness of red; this would serve to illustrate just what non-color property Peacocke has in mind. One of Peacocke's examples might be thought to fit the bill. "[W]hen facing towards the noonday sun with eyes closed, there can be red' regions of one's visual field without a surface, volume, external event or object looking red" (2008: 22). But, whether or not something looks red in such a situation, one is surely aware of a color, in particular yellowish-red. (And of course it is no mystery why it is that particular color, given that the sunlight is diffused through one's blood-filled eyelids.) So this example is not, after all, a case where red' can be discerned without danger of confusing it with red. ${ }^{20}$

${ }^{20}$ It is not clear to us that Peacocke intends the example this way (see his earlier description of it on 8-9). 
Peacocke gives another example, of looking at a scene through "rose-tinted spectacles" (22; cf. 1983: 38-9, 1984: 59). A white object in the scene looks white, but it is presented "in a pinkish' region of one's visual field". Provided one is not aware of pink, then this is an example of the required sort. However, the natural way of describing the object is as white and illuminated by pink light. Hence one is aware of pink, for that is the apparent color of the illuminant. ${ }^{21}$

If regions of the visual field have primed properties such as red', and physical objects are colored, then reductive dispositionalism is a natural view to hold. This is cold comfort, since the search for red' has come up empty.

\subsection{Natural signs and vision science}

There are some superficial similarities between the natural sign theory and modern empirical approaches to the study of vision. Electrophysiology, measurement of the electrical activity of neurons, has been an important aspect of vision science for the last fifty years. One of the most important kinds of data comprises recordings from single cells used to characterize their receptive field properties. Single-cell recordings are commonly taken as evidence for what properties, proximal or distal, the activity of the cell encodes. Cells later in the visual pathway can then use this activity as a sign of whatever environmental information is encoded. Here we have something that might look very much like the natural sign theory in operation at the sub-personal level. Although it is later neurons, rather than people, that interpret earlier neuronal activity, the similarity in basic structure might suggest that "neural" reductive dispositionalism for perception in general should be lurking in the vicinity. In the case of color perception, it would be of this sort: the property green $=$ the disposition to cause in perceivers of kind $P$ in conditions of kind $C$, neural activity of kind $N^{22}$

However, nothing like reductive dispositionalism has figured in empirical discussions of color vision, and the reason is that the "neural signs" are taken to be signs of ecologically relevant environmental features like illumination and reflectance, which are not themselves dispositions to cause neural activity. The dominant approach is to assume that neurons encode such stimulus features, and to take these representational facts as basic. ${ }^{23}$ The fundamental task of vision science on this view is to understand the mechanisms that establish the covariation between neural activity responses and these environmental features. If what one wants to understand is how the illuminationvarying cone outputs drive the illumination-independent response of cells in some extrastriate cortical areas, then the observation that cone outputs encode the informa-

\footnotetext{
${ }^{21}$ Cf. Peacocke's apt but slightly less natural description: "the experience as of a white object seen through pink glass" (22). For further discussion of this kind of case, see Hilbert 2005.

22 This is not a possibility that seems to have played much role in philosophical discussions of color. A view with some similarities, although at the personal level and complicated by intentionalist assumptions, is defended in Harman 1996.

${ }^{23}$ An early clear statement of this view can be found in opening chapters of Marr's influential textbook (1982).
} 
tion that there is something in the environment disposed to cause cone outputs is not to the point.

These considerations do not show that neural reductive dispositionalism is false, but they do show that it receives no support from the practice of vision science.

\section{Is non-reductive dispositionalism a "conceptual truth"?}

Reductive dispositionalism looks unpromising, to say the least. In this section and the next we consider the case for non-reductive dispositionalism. Perhaps remarkably, that version has struck many philosophers as something close to self-evident. For example, David Wiggins writes: "Surely it is simply obvious that colour is something subjective", which in the context clearly refers to non-reductive dispositionalism (1987: 189). According to Colin McGinn, it is a "logical or conceptual" truth that $x$ is red iff $x$ (standardly) seems red (1983: 6 and n. 2); and "[i]t is a conceptual truth that red things typically look red" (11). McGinn does not supply any argument for this himself, saying that "others have argued convincingly for the key points" (2).

Is there anything to be said for these claims? The notion of a conceptual (or "analytic") truth is obscure. One way of clarifying it, following Quine (1951), is to say that $S$ is a conceptual truth iff $S$ can be turned into a logical truth by substituting synonyms for synonyms. Thus, if is disposed to look red is synonymous with is red, then $x$ is red iff $x$ is disposed to look red is a conceptual truth. But, as we saw in section 2.1, there are compelling reasons to deny the synonymy.

Another idea is that $S$ is a conceptual truth if and only if $S$ is true and anyone who understands $S$ is disposed to assent to it. Thus stable denial of the dispositionalist biconditional would manifest incomplete understanding of the terms involved. It is quite doubtful whether any truth, even the most elementary logical truth, counts as conceptual by this test (see Williamson 2007: ch. 4), but the dispositionalist biconditional certainly doesn't. The view that material objects are not colored, despite being disposed to look colored, has enjoyed a long and popular following, including (waiving scholarly qualifications) Descartes, Malebranche, Locke, Hume, and Kant, as well as many contemporary philosophers and color scientists. ${ }^{24}$ It is not credible that this reflects a failure to understand color vocabulary.

Alternatively, talk of "conceptual truth" could be disregarded in place of Wiggins's more prosaic claim that the dispositionalist biconditional is "simply obvious". The mathematician G. H. Hardy is said to have emerged from a long intense period of

\footnotetext{
${ }^{24}$ See Descartes 1644/1985: I.lxx, Malebranche 1678/1997: 10, Replies to Second Objection, Locke 1689/1975: II.viii.17, Hume 1740/1978: I.iv.iv, Kant 1787/1933: A28-9. In support of the "eliminativist" interpretation of Locke, see Alexander 1976-77, Smith 1990, and Wilson 1992 for more general discussion. For some contemporary philosophical examples of eliminativism, see Mackie 1976, Jackson 1977, Boghossian and Velleman 1989, Landesman 1989, Boghossian and Velleman 1991, Averill 1992, Hardin 1993, Maund 1995, Clark 1996. For some professions of eliminativism from color scientists, see Maund 1995: 27-9.
} 
contemplation with the announcement that a certain theorem was indeed obvious. As the above list of distinguished dissenters indicates, if the dispositionalist biconditional is obvious, it can only be in this Pickwickian sense. ${ }^{25}$

\section{Johnston's argument for (non-reductive) dispositionalism}

Johnston appears to endorse something like the Reidian version of the natural sign theory in his important paper "How to speak of the colors" (1992). Therefore the dispositionalism he defends ought to be the reductive sort. However, most of the time he writes in a non-reductive manner of dispositions "to look red", "experiences as of a canary yellow thing", and so forth. ${ }^{26}$ Partly because of this, the non-reductive dispositionalist might well think he can co-opt Johnston's case for dispositionalism. For that reason, as well as for the argument's considerable intrinsic interest, we need to consider it here. ${ }^{27}$

According to Johnston, for broadly pragmatic considerations we ought to adopt a certain dispositional conception of the colors. The argument runs roughly as follows. No properties fit all our naive "core beliefs" about color (those beliefs such that their falsity would incline us towards eliminativism about color). But it would be a "characteristic fallacy" (142), familiar from debates about eliminativism in the philosophy of mind, to conclude that no physical objects are colored. That would be like saying, to borrow an example from David Lewis, that since the special theory of relativity shows us that simultaneity cannot be a frame-independent equivalence relation, no one ever whistled while he worked. For in fact there are relations that fit enough of our core beliefs about simultaneity to be rightly called simultaneity — and enough need not mean all. Similarly, Johnston argues, in the case of color. According to Johnston, two candidates stand out as good enough to be the colors - the physical properties that typically cause our color experiences ("the Primary Quality View"), and "typically realized" dispositions to look colored. Which of these two candidates is the least imperfect deserver of the color names? Here Johnston makes an ingenious appeal to "something we very much value: acquaintance with the colors" (167). It is, Johnston

\footnotetext{
25 One argument in the vicinity is that colors are dispositions because that it the way they look (Langsam 2000). We are setting this aside because the usual claim is the reverse, that colors don't look like dispositions (Boghossian and Velleman 1989, McGinn 1996; a qualified endorsement of this claim is in Johnston 1992). Langsam's argument is examined in Byrne 2001; for a related discussion, see Levin 2000.

${ }^{26}$ Although sometimes the terminology has a strong reductivist flavor: "if teal is essentially the disposition to manifest a certain appearance Te and turquoise is essentially the disposition to manifest the appearance Tq" (152, our italics).

27 We should emphasize that Johnston now disowns dispositionalism, and holds a primitivist view similar to Campbell's (1993) and Yablo's (1995): objects generally have the colors they appear to have, and the colors cannot be identified with either psychological dispositions or physical properties. (See, in particular, Johnston 1997, 1998, and his in-progress manuscript The Manifest.) But the argument of "How to Speak of the Colors" deservedly remains influential. (For a critical discussion of primitivism, see Byrne and Hilbert 2007.)
} 
says, "somewhat obscure" just what acquaintance with a property ("knowing the nature of a property") amounts to (164). But we have enough of a grasp of it, he argues, to see that dispositions to look colored are properties with which vision can acquaint us, and physical properties are not. Hence, "[t]he ultimate defect of the Primary Quality View is therefore a practical one. From the point of view of what we might call the ethics of perception, the Secondary Quality Account is to be preferred. It provides for acquaintance with the colors" (167).

We should look askance at the final step—that we should "refigure" our color concepts to favour dispositionalism because this will allow us "to secure an important cognitive value", acquaintance with the colors (167). What does "refiguring our color concepts" amount to? It seems to involve using our color vocabulary much as before, but now meaning something slightly different by it. So although the typically realized disposition to look crimson is not a perfect candidate for the referent of crimson, Johnston is recommending that we henceforth use color terminology so that this property is a perfect candidate.

But such a revision will not satisfy the original desire to be acquainted with the colors. To be sure, assuming Johnston is right about acquaintance, after the revision we will speak truly when we utter We are acquainted with the colors. But that doesn't help. Example: suppose I want to be loved by Lara (a goddess who, I subsequently discover, is merely a fictional character). I am in fact loved by Cara (a flesh-and-blood approximation to Lara). I now call Cara Lara, and so can henceforth truly utter I am loved by Lara. Were love so easily requited!

In fact, Johnston doesn't need this argument to break the tie between dispositionalism and the Primary Quality View. For by his own lights, dispositions do better than physical properties at satisfying our "core beliefs" about the colors (see especially 149-54).

Taking canary yellow as an example, the "core beliefs" may be summarized thus (see 138):

(1) Paradigms: "Some of what we take to be paradigms of canary yellow things (e.g. some canaries) are canary yellow".

(2) Explanation: The fact of something's being canary yellow "sometimes causally explains our visual experiences as of canary yellow things".

(3) Unity: canary yellow stands in certain similarity, difference, and exclusion relations to the other colors (e.g. "canary yellow is not as similar to the shades of blue as they are similar among themselves").

(4) Perceptual Availability: "Justified belief about the canary yellowness of external things is available simply on the basis of visual perception ... and general background beliefs".

(5) Revelation: "The intrinsic nature of canary yellow is fully revealed by a standard visual experience as of a canary yellow thing". 
According to Johnston, the disposition to look canary yellow satisfies (1)-(4). ${ }^{28}$ (The fifth core belief is somewhat elusive, as Johnston admits; we do not need to discuss it further here. $)^{29}$ However, there are two serious objections to concluding from this that the disposition to look canary yellow is, at least loosely speaking, the property canary yellow.

The first is this. There are properties one can visually detect only by having appropriate background knowledge (of a relatively sophisticated sort). For example, take being a cricket ball. Given appropriate background knowledge (that cricket balls are red, round, leathery ...), one can use one's eyes to acquire knowledge that an object is a cricket ball; on the other hand, someone who had no knowledge of cricket would be unable to recognize cricket balls as such. Let us say that these sorts of properties are indirectly available. Other properties are directly available: no specific relatively sophisticated background knowledge is required in order to acquire knowledge about the shape of a cricket ball. (This distinction is obviously vague; for our purposes this is harmless, since we will only appeal to clear cases.)

Now, could it turn out that a property is canary yellow, at least loosely speaking, even though it was indirectly available? Arguably not. A property that could only be visually detected with a suitable stock of relatively sophisticated background knowledge would be an extremely imperfect deserver of the name canary yellow. ${ }^{30}$ So, if we are to conclude that the disposition to look canary yellow is the property canary yellow, then we need to establish that this disposition is directly available. But it is quite unclear how this might be done. Notice that satisfying (1)-(4) does not suffice for direct availability. The first core belief gives a necessary condition, the second two are not relevant, and the fourth (ignoring the difference between knowledge and justified belief) merely imposes the constraint that the property in question is either indirectly available or directly available.

Once the first objection has been stated, a second, more conclusive, objection immediately suggests itself. For there is a directly available property-call it CYthat objects like canaries, some New York taxi cabs, and legal notepads visually appear to have. ${ }^{31}$ (At least, CY is directly available if canaries and the like actually possess it.) Surely if any property is canary yellowness, CY is canary yellowness: imagine looking at a canary, a canary yellow taxi cab, and a legal notepad; attend to the distinctive way that they each appear; slowly say to yourself "Maybe this is not the best candidate for being the property canary yellow”. It doesn't matter whether we can find a disposition

\footnotetext{
${ }^{28}$ It is clear what Johnston means by saying that a property $\mathrm{P}$ "satisfies" a core belief (n). In the sentence expressing $(\mathrm{n})$, replace all occurrences of canary yellow [ness] with the property canary yellow, making adjustments for grammar. So, e.g. canary yellow things becomesthings that have the property canary yellow. However, leave visual experience as of a canary yellow thing and its plural untouched. Now replace every occurrence of the property canary yellow with a name of $\mathrm{P}$. $\mathrm{P}$ satisfies (n) iff the result is true.

${ }^{29}$ For further discussion, see Byrne and Hilbert 2007.

${ }^{30}$ Here we are granting for the sake of the argument the neo-description theory of reference that Johnston is assuming, on which canary yellow is the property that best fits our "core beliefs" about it. We do not think this theory is correct, however.

31 Cf. Johnston 1997: 174, on the "visual concept of canary yellow."
} 
that is possessed by canaries, that stands in the right similarity relations, and so forth; if it isn't CY, then it's not the property canary yellow. But Johnston supplies no argument that this disposition is $\mathrm{CY}{ }^{32}$

So, to summarize, Johnston's pragmatic argument for dispositionalism and his more straightforward "best candidate" argument are both mistaken.

If we recall Johnston's apparent endorsement of the natural sign theory, then it becomes perfectly understandable why directly available properties like CY were overlooked. Color perception, on the natural sign theory, is a matter of figuring out the properties of external things from their "known effects", as one might try to reconstruct the murder from the pattern of blood drops. Relatively sophisticated background knowledge will thus be needed if color experience is to yield knowledge about the properties of external things. In other words, according to the natural sign theory no properties of external things are directly available in color experience, and in particular there is no such property as $C Y$.

\section{Summing up}

Janet Levin has defended dispositionalism against the complaint that it fails to respect the phenomenology of color experience. Her starting point is clear: "In fairly recent work, both Colin McGinn and Mark Johnston have (in my view ably and effectively) defended a dispositional theory of color on the grounds that it best conforms to our common sense views about what sorts of properties colors are" (2000: 152); she then goes on ably and effectively to deflect the complaint. This paper has questioned Levin's starting point: the major contemporary arguments for dispositionalism have all been found wanting. Perhaps other arguments will do the job: the paper presents a challenge to dispositionalists, not a refutation.

What is completely misguided, or so we have argued, is the natural sign theory. Getting rid of that removes the central motivation for reductive dispositionalism. More importantly, it restores the thought that we have better than second-hand epistemic access to the properties of external things.

Non-reductive dispositionalism fares slightly better than its reductive counterpart. Although the frequent claim that it is a "conceptual truth" or some such is most improbable, there is no lurking incoherence in the view. Still, the influence of the pernicious natural sign theory is present even here, as we saw at the end of our discussion of Johnston's argument.

In any event, what needs emphasizing is that non-reductive dispositionalism is not of any great philosophical moment. The property that the non-reductive dispositionalist identifies with the color red is one that objects uncontroversially have-tomatoes and

\footnotetext{
32 Cf. Yablo 1995: 485: "the claim here is that yellowness is itself something familiar and known; our ordinary, non-expert ways of conceiving it tell as good as story as any about what it is." The present objection appeals to the part before the semi-colon, not the part after.
} 
the like are disposed to look red to certain humans in certain conditions. That tomatoes have such dispositions will not overturn any apple carts: in particular, it does not imply that tomatoes are partly constituted by us, or have "subjective properties", in some philosophically important sense of that phrase. ${ }^{33}$

Further, granted that tomatoes and the like actually are red, the color and the dispositional property are at the very least often coinstantiated. All that dispositionalism adds is that the disposition to look red is identical to (and so is necessarily coinstantiated with) a certain directly available property — redness. This addition simply identifies the disposition as a property that the human color vision system is in the business of detecting. Without the addition, the perceived world is not interestingly subjective; with the addition, the situation remains unchanged. Further, non-reductive dispositionalism does not constrain the nature of redness in any significant way-it is perfectly compatible with the view that colors are physical properties of a certain sort, for example. The chief problem with non-reductive dispositionalism is not falsity, but insipidity.

\section{Bibliography}

Alexander, P. 1976-77. "The Names of Secondary Qualities," Proceedings of the Aristotelian Society 77: 203-20.

Armstrong, D. M. 1968a. A Materialist Theory of the Mind, New York: Humanities Press.

Averill, E. W. 1992. “The Relational Nature of Color,” Philosophical Review 101: 551-88.

Block, N. 1990. "Inverted Earth," Philosophical Perspectives 4: 53-79.

Boghossian, P. A., and J. D. Velleman. 1989. "Colour as a Secondary Quality." Mind 98: 81-103. Reference to the reprint in Byrne and Hilbert 1997b.

—. 1991. "Physicalist Theories of Color," Philosophical Review 100: 67-106.

Broackes, J. 1992. “The Autonomy of Colour,” Reduction, Explanation and Realism. ed. D. Charles and K. Lennon, Oxford: Oxford University Press. Reference to the reprint in Byrne and Hilbert 1997b.

Brown, D. 2006. "On the Dual Referent Approach to Colour Theory," Philosophical Quarterly 56: 96-113.

Byrne, A. 2001. "Do Colours Look Like Dispositions? Reply to Langsam and Others," Philosophical Quarterly: 238-45.

—. 2009a. "Sensory Qualities, Sensible Qualities, Sensational Qualities," The Oxford Handbook of Philosophy of Mind. ed. B. McLaughlin, A. Beckermann, and S. Walter, Oxford: Oxford University Press.

—. 2009b. "Experience and Content," Philosophical Quarterly 59: 429-51.

Byrne, A. and D. R. Hilbert. 1997a. "Colors and Reflectances," Readings on Color, Volume 1: The Philosophy of Color. ed. A. Byrne and D. R. Hilbert, Cambridge, MA: MIT Press.

Byrne, A. and D. Hilbert. 2007. "Color Primitivism," Erkenntnis 66: 73-105.

—. (eds.). 1997b. Readings on Color, Volume 1: The Philosophy of Color, Cambridge, MA: MIT Press.

${ }^{33}$ For a potent antidote to the tendency to think otherwise, see Rosen 1994. 
Campbell, J. 1993. "A Simple View of Colour," Reality, Representation and Projection, ed. J. Haldane and C. Wright, Oxford University Press.

Clark, A. 1996. "True Theories, False Colors," Philosophy of Science 63: S143-50.

Descartes, R. 1644/1985. Principles of Philosophy. The Philosophical Writings of Descartes, Volume 1, translated by J. Cottingham, R. Stootfhoff and D. Murdoch, Cambridge: Cambridge University Press.

- 1664/1985. The World or Treatise on Light: The Philosophical Writings of Descartes, Volume 1, translated by J. Cottingham, R. Stootfhoff, and D. Murdoch, Cambridge: Cambridge University Press.

Firth, R. 1949. "Sense-Data and the Percept Theory,” Mind 58: 434-65.

Glüer, K. 2007. "Colors Without Circles?” Erkenntnis 66: 107-31.

Hardin, C. L. 1993. Color for Philosophers: Unweaving the Rainbow (expanded edition), Indianapolis: Hackett.

Harman, G. 1996. "Explaining Objective Color in Terms of Subjective Reactions," Philosophical Issues 7: 1-17. Reference to the reprint in Byrne and Hilbert 1997b.

Hilbert, D. R. 1987. Color and Color Perception: A Study in Anthropocentric Realism, Stanford: CSLI. - 2005. "Color Constancy and the Complexity of Color," Philosophical Topics 33: 141-58.

Hume, D. 1740/1978. A Treatise of Human Nature, edited by L. A. Selby-Bigge, Oxford: Oxford University Press.

Jackson, F. 1977. Perception: A Representative Theory, Cambridge: Cambridge University Press.

—. 1998. From Metaphysics to Ethics: A Defence of Conceptual Analysis, New York: Oxford University Press.

Jackson, F and R. Pargetter. 1987. "An Objectivist's Guide to Subjectivism about Colour," Revue Internationale de Philosophie 41: 127-41. Reference to the reprint in Byrne and Hilbert 1997b.

Johnston, M. 1992. "How to Speak of the Colors," Philosophical Studies 68: 221-63. Reference to the reprint in Byrne and Hilbert 1997b.

. 1997. "Postscript: Visual Experience," Readings on Color, Volume 1: The Philosophy of Color, ed. A. Byrne and D. R. Hilbert, Cambridge, MA: MIT Press.

_. 1998. "Are Manifest Qualities Response-Dependent?” The Monist 81: 3-43.

—. 2001a. "Is Affect Always Mere Effect?” Philosophy and Phenomenological Research 63: 225-8.

- 2001b. "The Authority of Affect," Philosophy and Phenomenological Research 63: 181-214.

Kant, I. 1787/1933. Critique of Pure Reason, translated by N. K. Smith, London: Macmillan.

Landesman, C. 1989. Color and Consciousness: An Essay in Metaphysics, Philadelphia: Temple University Press.

Langsam, H. 2000. "Why Colours Do Look Like Dispositions,” Philosophical Quarterly 50: 68-75.

Langton, R. 1998. Kantian Humility, Oxford: Oxford University Press.

Levin, J. 2000. "Dispositional Theories of Color and the Claims of Common Sense," Philosophical Studies 100: 151-74.

Lewis, D. 1997a. "Finkish Dispositions," Philosophical Quarterly 47: 143-58.

—. 1997b. "Naming the Colors," Australasian Journal of Philosophy 75: 325-42.

Locke, J. 1689/1975. An Essay Concerning Human Understanding, Oxford: Oxford University Press. McGinn, C. 1983. The Subjective View: Secondary Qualities and Indexical Thoughts, Oxford: Oxford University Press.

—. 1996. “Another Look at Color," Journal of Philosophy 93: 537-53. 
Mackie, J. L. 1976. Problems From Locke, Oxford: Clarendon Press.

Malebranche, N. 1678/1997. The Search After Truth: With Elucidations of The Search After Truth, translated by T. M. Lennon and P. J. Oscamp, Cambridge: Cambridge University Press.

Marr, D. 1982. Vision: A Computational Investigation into the Human Representation and Processing of Visual Information, San Francisco: W. H. Freeman.

Matthen, M. 1988. "Biological Functions and Perceptual Content," Journal of Philosophy 85: 5-27. Maund, J. B. 1995. Colours: Their Nature and Representation, Cambridge: Cambridge University Press. Moore, G. E. 1959. “A Defence of Common Sense,” Philosophical Papers, London: Allen \& Unwin. Peacocke, C. 1983. Sense and Content: Experience, Thought, and their Relations, Oxford: Oxford University Press.

—. 1984. "Colour Concepts and Colour Experience," Synthese 58: 365-82. Reference to the reprint in Byrne and Hilbert 1997b.

- 2008. "Sensational Properties: Theses to Accept and Theses to Reject," Revue Internationale de Philosophie 62: 7-24.

Prior, E., R. Pargetter, and F. Jackson. 1982. "Three Theses About Dispositions," American Philosophical Quarterly 19: 251-7.

Quine, W. V. O. 1951. "Two Dogmas of Empiricism,” Philosophical Review 60: 20-43.

Reid, T. 1785/1941. Essays on the Intellectual Powers of Man, edited by A. D. Woozley, London: Macmillan.

Rosen, G. 1994. “Objectivity and Modern Idealism: What is the Question? Philosophy in Mind: The Place of Philosophy in the Study of Mind, ed. M. Michael and J. O'Leary-Hawthorne.

Russell, B. 1912. The Problems of Philosophy, Oxford: Oxford University Press.

Sellars, W. 1956. "Empiricism and the Philosophy of Mind," Minnesota Studies in the Philosophy of Science, ed. H. Feigl and M. Scriven.

Shoemaker, S. 1982. “The Inverted Spectrum,” Journal of Philosophy 79: 357-81. 1994. "Phenomenal Character," Nos 28: 21-38. Reference to the reprint in Byrne and Hilbert 1997b.

Smith, A. D. 1990. “Of Primary and Secondary Qualities,” Philosophical Review 99: 221-54.

Stroud, B. 2000. The Quest for Reality: Subjectivism and the Metaphysics of Colour, New York: Oxford University Press.

Tye, M. 1995. Ten Problems of Consciousness: A Representational Theory of the Phenomenal Mind, Representation and mind, Cambridge, MA: MIT Press.

- 2000. Consciousness, Color, and Content, Cambridge, MA: MIT Press.

Van Cleve, J. 1999. Problems from Kant, Oxford: Oxford University Press.

Watkins, M. 1994. "Dispositionalism, Ostension, and Austerity," Philosophical Studies 73: 55-86.

Wedgwood, R. 2001. "Sensing Values?” Philosophy and Phenomenological Research 63: 215-23.

Wiggins, D. 1987. “A Sensible Subjectivism?” Needs, Values, Truth, Oxford: Basil Blackwell.

Williamson, T. 2007. The Philosophy of Philosophy, Oxford: Blackwell.

Wilson, M. D. 1992. "History of Philosophy in Philosophy Today; and the Case of the Sensible Qualities,” Philosophical Review 101: 191-243.

Wittgenstein, L. 1958. Philosophical Investigations, 2nd ed. Oxford: Basil Blackwell.

Yablo, S. 1995. "Singling out Properties," Philosophical Perspectives. ed. J. Tomberlin, Atascadero, CA: Ridgeview. 